\title{
Salmonella spp., importante agente patogênico veiculado em alimentos
}

\author{
Salmonella spp., important pathogenic agent \\ transmitted through foodstuffs
}

\author{
N eide Kazue Sakugawa Shinohara ${ }^{1}$ \\ VivianeBezerra de Barros ${ }^{2}$ \\ Stella M aris Castro Jimenez ${ }^{2}$ \\ Erilane de Castro Lima M achado ${ }^{3}$ \\ Rosa Amália Fireman Dutra ${ }^{4}$ \\ José Luiz de Lima Filho ${ }^{4}$
}

${ }^{1}$ Departamento de

Tecnologia Rural,

Universidade Federal Rural dePernambuco. RuaDom $M$ anoel de $M$ edeiros $s / n$, Dois Irmãos. 52171-900 Recife PE.

shino@dtr.ufrpe.br

${ }^{2}$ FaculdadeFrassinetti do

Recife.

${ }^{3}$ Departamento de Nutrição,

Universidade Federal de

Pernambuco.

${ }^{4}$ Laboratório de

Imunopatologia Keizo

Asami, Universidade

Federal dePernambuco.
Abstract The occurrence of foodborne diseases has been a matter of discussion over the last years due to the worldwide concern with strategies for their control and for ensuring that safe food products reach the consumer. Salmonella spp. isamong the most widespread microorganisms in nature, having man and animals as main natural reservoirs. With occurrence of regional serotypes causing salmonell osis, this pathogen is considered one of the main agents responsible for outbreaks of foodborne diseasein the developing countries. The increasing incidence of salmonellosis caused by contaminated food has shown that, despite the recent technological improvements, this problem still occurs in all countries. Cattleand poultry are the main responsible for the transmission of this pathogenic agent. Due to its wide distribution in animals, the existence of asymptomatic carriers and its presence in foodstuff and in the environment Salmonella spp. representsa significant public health problem worldwide calling for permanent control programs and eradication strategies. Key words Salmonella spp., Foodborne disease, Control program
Resumo A ocorrência de doenças transmitidas por alimentos (DTAs) tem sido foco de discussões nos últimos anos, devido à preocupação mundial com estratégias que permitam seu controle e, conseqüentemente, garantam a colocação de produtos seguros no mercado consumidor. A Salmonella spp. é um dos microrganismos mais amplamente distribuídos na natureza, sendo o homem e os animais seus princi pais reservatórios naturais, com ocorrência de sorotipos regionais, reconhecidos como salmoneloses, e considerado como um dos principais agentes envolvidos em surtos de origem alimentar em países desenvolvidos. 0 aumento da incidência da salmonelose provocada por alimentos contaminados demonstra que, na atualidade, apesar dos avanços tecnológicos alcançados, este problema ainda ocorre mundialmente. As aves e bovinos são responsáveis pela maior disseminação desse agente patogênico. A ampla distribuição da Salmonella spp. entre os animais, a existência de portadores assintomáticos e sua permanência no ambiente e nos alimentos contribuem para que este microrganismo assuma um papel de grande relevância na saúde pública mundial e, portanto, programas permanentes de controle e erradicação devem ser adotados.

Palavras-chaveSalmonella spp., I nfecção alimentar, Programa de controle 
Introdução

Considerando que a maioria dos quadros de gastroenterite transcorre sem a necessidade de hospitalizações e sem 0 isolamento do agente causal no alimento incriminado, a ocorrência das salmoneloses na população humana transmitida por alimentos é provavelmente subestimada ${ }^{1}$. Vale salientar que a subnotificação dos surtos de origem alimentar pelos serviços de vigilância epidemiológica é uma realidade mundial ${ }^{2}$. Segundo Forsythe e Germano $0^{3,4}$, somente $10 \%$ do total de surtos de origem alimentar são notificados no Brasil, devido às falhas no sistema de notificação edefiscalização.

Houvemudanças no perfil epidemiológico de enfermidades transmitidas por alimentos devido à expansão dos mercados de consumo, a globalização econômica, alterações dos hábitos alimentares eaumento no consumo dealimentos industrializados ou produzidos fora do lar; porém, as doenças veiculadas por al imentos continuam sendo uma das principais causas de morbidade nos países da América Latina e Caribe ${ }^{5,6}$. No Brasil, as doenças infecciosas, parasitárias e do aparelho digestivo corresponderam a 9,2\% do total de casos de mortalidade, sendo as regiões do Norte e Nordeste brasileiro as mais afetadas?.

A Salmonella spp. éuma bactéria entérica responsável por graves intoxicações alimentares, sendo um dos principais agentes envolvidos em surtos registrados em vários países-12. A sua presença em alimentos é um relevante problema de saúde pública que não deve ser tolerado nos países desenvolvidos, e principalmente nos países em desenvolvimento, porque os sinais e sintomas podem ser mal diagnosticados, sobrecarregando ainda mais todo o sistema de saúde ${ }^{13}$. Devemos ressaltar que a maioria dos sorotipos desse gênero são patogênicos ao homem, apresentando diferenças de sintomatologia em de corrência da variação no mecanismo de patoge nicidade, além da idade e da resposta imune do hospedeiro ${ }^{14-16}$.

A salmonelose éuma das principais zoonoses para a saúde pública em todo o mundo ${ }^{17}$, exteriorizando-se pela suas características deendemicidade, alta morbidade e, sobretudo, pela dificuldadeda adoção demedidano seu controle ${ }^{18}$. Além da importância das medidas preventivas para evitar o risco de infecção da salmonel ose na população humana, o controle desta doença é de grande interesse para a economia dos países em que ocorrem esses surtos. Os custos estimados da alta incidência da salmonelose nos Estados Unidos va- riaram entre $\$ 1,3$ a $\$ 4,0$ bilhões por ano, em de corrência de despesas médicas, ausência ao trabalho e quebras na produtividade ${ }^{19}$.

O Brasil, como grande exportador mundial de carne bovina e de aves ${ }^{20}$, deve estabelecer medidas de controle sanitário cada vez mais rígidas, evitando assim grandes prejuízos devido às perdas indiretas, através de embargos econômicos impostos pelos países importadores.

Em função dos riscos que esse importante patógeno representa para a saúde dos consumidores, o objetivo dessa revisão é promover uma breve descrição da Salmonella spp. quanto à sintomatologia, patogenicidade, ocorrência nos vários grupos de alimentos e as formas de prevenção e controle da Salmonella spp.

\section{Sintomatologia \\ etransmissão da Salmonella}

A grande maioria dos sorotipos de salmonelas são patogênicas para o homem, de forma que os sintomas clínicos podem ser divididos em três grupos ${ }^{21-25}$ :

- A febre tifóide, causada por S. typhi, que só acomete o homem enão possui reservatórios em animais. N ormalmente, a forma de disseminação da infecção éinterpessoal e através da água e alimentos contaminados com material fecal humano. Os sintomas são muito graves e incluem septicemia, febre alta, diarréia e vômitos. A pós a infecção, os indivíduos podem se tornar portadores por meses ou anos, constituindo então uma fonte contínua de infecção. Podemos citar como exemplo padrão de portador de longo termo, M ary Typhoid, uma cozinheira da cidadedeNova York que, no início de 1990, foi responsável por aproximadamente dez surtos na época. A proximadamente 1 a $3 \%$ dos pacientes com febre entérica tornam-se portadores crônicos. 0 estado deportador crônico é mais comum em mulheres e em idosos, bem como naqueles com problemas de vesícula biliar, porque é o local mais comum de alojamento dos portadores de salmonelas. A febre tifóide pode evoluir para óbito, caracterizada por septicemia, febre contínua, cefaléia e diarréia. 0 período de incubação usualmente varia de 7 a 21 dias ea duração da doença pode chegar a oito semanas.

- Na febreentérica, 0 agenteetiológico éa Salmonella paratyphi A, B e C, os sintomas clínicos são mais brandos que em relação à febre tifóide, podendo evoluir para septicemia efreqüentemente desenvolver um quadro de gastroenterite, fe- 
bre e vômitos. 0 período de incubação é usualmente de 6 a 48 horas e a duração média da doençaé de três semanas. Essa doença pode ser causada pelo consumo deágua eal imentos, especialmente leite e vegetais crus, mariscos e ovos.

- Asinfecções entéricas em decorrência deoutras salmonelas, ou também chamadas de salmoneloses, desenvolvem um quadro de infecção gastrointestinal, tendo como sintomas dores abdominais, diarréia, febre baixa e vômito, sendo raro os casos clínicos fatais. Os sintomas aparecem de 12 a 36 horas, podendo durar os sintomas até 72 horas. Trata-se da manifestação mais comum de infecção por Salmonella e o episódio geralmente sofre resolução em dois a três dias, não necessitando de tratamento com antibióticos. Os alimentos mais incriminados são carne bovina, aves, suíno e ovos crus.

\section{M ecanismo de patogenicidade e terapêutica da Salmonella}

Salmonella é uma bactéria que causa doenças em humanos e animais, através do consumo e da ingestão dealimentos contaminados. As espécies desse gênero atravessam a camada epitelial intestinal, al cançam a lâmina própria (camada na qual as células epiteliais estão ancoradas) , onde proliferam. São fagocitadas pelos monócitos e macrófagos, resultando em resposta inflamatória, decorrente da hiperatividade do sistema reticuloendotelial. Ao contrário do queocorrena febre tifóide, nas enterocolites, a penetração deSalmonella spp. fica limitada à lâmina própria. N estes casos, raramente se observa septicemia ou infecção sistêmica, ficando a infecção restrita à mucosa intestinal. A resposta inflamatória está relacionada também com a liberação de prostaglandinas, que são estimuladoras deadenilciclase, o que resulta em um aumento de secreção de água e eletrólitos, provocando diarréia aquosa ${ }^{22,26,24}$.

O sorotipo predominante causador de infecções alimentares mudou nas últimas décadas de S. agona, S. hadar eS. typhimurium para S. enteritidis, sendo a $\mathrm{S}$. enteritidis a causa predominante de salmoneloses em diversos países ${ }^{27,11}$. Alterações nos sorotipos refletem mudanças na criação do animal e a disseminação de novos sorotipos devido ao grande fluxo do comércio mundial. A principal grande preocupação na atualidade éo aparecimento de sorotipos do gênero Salmonella multirresistentes a antibióticos ${ }^{28,16}$.

Um grandenúmero desalmonelas precisa ser ingerido para que ocorra a gastroenterite; nor- malmente a dose infectante depende do sorotipo

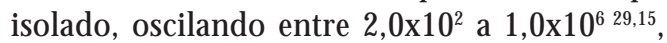
também ocorre variação quanto ao alimento envolvido e a espécie de Salmonella em estudo, pois espécies adaptadas ao homem necessitam de doses infectantes menores que as não adaptadas para provocar a mesma sintomatologia característica da doença. Entretanto, algumas vezes a doença pode ser fatal em crianças, idosos ou imunocomprometidos, devido à menor resistência às infecções ${ }^{30}$.

0 tratamento com antibacterianos deve ser iniciado tão logo seja diagnosticada a febretifóide ou a febre entérica e o tratamento deve ser mantido pelo menos uma semana após a temperatura ter voltado ao normal, para que possa atingir a Salmonella em sua local ização intracelu$\operatorname{lar}^{24}$. Antes do advento dos antibióticos, a taxa de mortali dadeera de 10 a 15\%; com a prática da terapia a base de antibióticos, essa taxa foi reduzida para menos de $1 \%{ }^{23}$. Com exceção daS. typhi e S. paratyphi, as outras salmonelas geralmente apresentam quadro clínico autolimitante com reversão espontânea em 48 horas, e a administração de antibióticos no tratamento das gastroenterites não é recomendado, pois prolonga 0 período de excreção do agente, caracterizando o portador assintomático, além de promover o aparecimento desalmonelas multirresistentes ${ }^{11,16}$.

\section{Dados epidemiológicos}

Vários são os fatores que contribuem para o surgimento ou aumento da patogenicidade de várias doenças, entre os quais se destacam: 0 crescente aumento da população, a existência de grupos populacionais vulneráveis ou mais expostos, 0 processo deurbanização desordenado ea necessidade de produção de alimentos em grande escala industrial. Aliado a todos esses fatores, contribui ainda o deficiente controle dos órgãos públicos e privados, no tocante à qualidade dos alimentos disponíveis para consumo às populações ${ }^{31}$.

A higiene dos alimentos tem como principal objetivo o estudo de métodos para a produção, acondicionamento e distribuição dos alimentos dentro de limites de segurança microbiológica, abrangendo não só a manipulação dos gêneros alimentíciose de bebidas, mas também o emprego de utensílios e equipamentos para o seu preparo, uso de matéria-prima de boa procedência, adoção de boas práticas de higiene pessoal dos manipuladores equalidadehigiênico-sanitário da área de preparação ${ }^{32,33}$. Para ilustrar a impor- 
tância da mani pulação na preparação dealimentos, foi realizado um inquérito para avaliar o nível de conscientização e adoção de práticas higiê nico-sanitárias demanipuladores domésticos, em M elbourne, na Austrália, ondefoi constatado que $47 \%$ não higienizavam corretamente as mãos e $70 \%$ não realizavam a limpeza adequada das superfícies de preparação dos alimentos ${ }^{34}$. Os autores ressaltam que essas práticas inadequadas são os principais fatores que elevam as estatísticas da toxinfecção alimentar naquele país.

Em 1888, na Alemanha, Gurtner descreveu o primeiro surto de salmonelose, quando adoeceram 59 pessoas e o óbito de um jovem foi verificado 35 horas depois de ter ingerido 800 gramas de carne $\mathrm{crua}^{35}$. A patologia decorrente da Salmonella spp. se dá pela transmissão fecal-oral que ocorre através de água e alimentos contaminados, e a grande incidência é encontrada em populações com grande densidade populacional, vivendo em precárias condições higiênicas sanitárias e socioeconômicas ${ }^{21}$.

Uma ampla variedade de alimentos podem ser contaminados com a Salmonella spp., pois aqueles que possuem alto teor de umidade, de proteína e de carboidratos, como carne bovina, suínos, aves, ovos, leite e derivados, frutos do mar e sobremesas recheadas, são mais susceptíveis à deterioração ${ }^{11,36-40}$. Outros grupos de alimentos como frutas e vegetais minimamente processados também podem ser veiculadores de salmoneloses ${ }^{32,41}$, e essa contaminação ocorre devido ao controle inadequado da temperatura, da adoção de práticas de manipulação incorretas ou por contaminação de alimentos crus em contato com alimentos processados ${ }^{33,32,42}$.

A transmissão da Salmonella spp. para o homem geralmenteocorre pelo consumo dealimentos contaminados, embora a transmissão pessoa a pessoa possa ocorrer particularmente nos hospitais ${ }^{30}$ ou, ainda, através do contato com animais infectados, principalmente entre veterinários e trabalhadores de granjas e fazendas ${ }^{43}$. Segundo o Centro de Controle de Doenças (CDC), ocorrem anualmente, nos Estados Unidos, 40.000 casos de salmonelose e destes $90 \%$ são de origem alimentar, evoluindo para quinhentas mortes, o que classifica como importante patógeno de origem alimentar ${ }^{42}$.

A salmonelose, por não ser de notificação compulsória obrigatória no país, com exceção da febre tifóide ${ }^{31}$, torna difícil a coleta de dados quetenham significado estatístico, mas acreditase que a incidência dessas doenças seja bastante elevada entre a população ${ }^{44}$, sendo poucas as publicações científicas sobre o tema ${ }^{45}$; portanto, para se ter uma idéia dos agentes mais freqüentementeenvolvidos em surtos detoxinfecção alimentar, é necessário recorrer às estatísticas de países que possuem uma assistência médica mais eficaz e melhor organizada ${ }^{46}$. A pesar da importância da epidemiologia da febre tifóide, existe uma grande subnotificação no país por várias razões, incluindo inúmeros casos da doença que não são diagnosticados, dificuldades de acesso aos serviços de saúde, não reconhecimento de casos suspeitos e uso precoce de antimicrobianos em situações clínicas indefinidas, possibilitando o surgimento de cepas resistentes a antibióticos ${ }^{31}$.

Os pacientes com febre entérica que se tornam portadores crônicos continuam a excretar S. typhi nas fezes por várias semanas. Se esses pacientes não se submetem a um tratamento adequado, a doença pode evoluir por semanas ou até meses, resultando em óbito em $10 \%$ dos acometidos em decorrência das complicações secundárias (lesões gastrointestinais), enquanto que para os demais integrantes do gênero Salmonella não excede $1 \%^{24}$. Todavia, estas taxas podem ser maiores na dependência da associação de determinados sorotipos com a idade dos acometidos, como ocorre com a S. enteritidis em surtos com idosos em hospitais, onde a mortalidade pode atingir até $3,6 \%$ dos doentes ${ }^{14}$. Resultado semeIhante foi observado também por outros autores, que descrevem ser 0 índice de letalidade de cerca de $4,1 \%$ na mesma faixa etária ${ }^{42}$.

$\mathrm{Na}$ atualidade, ocorre variação no número de casos de febre tifóide e entérica, dependendo do país e das condições em que vivem as populações. Como exemplo, a incidência no Vietnã éde 198 ena Índia, de 980 para cada 100.000 habitantes, relação muito diferenteencontrada nos Estados Unidos, que é de 7 para cada 100.000 habitantes. Essa diferença é em decorrência das condições higiênico-sanitárias precárias em que vive a população, associada ao uso de água não tratada para consumo e higiene pessoal ${ }^{21}$. Segundo os autores, a estimativa mundial é de aproximadamente 16 milhões de novos casos de febre tifóide e entérica a cada ano e, desse total, 600.000 evoluem para óbito.

Segundo a Fundação N acional deSaúde ${ }^{31}$, em áreas endêmicas, acomete com maior freqüência indivíduos de 15 a 45 anos. No Brasil, nas últimas décadas, constata-se uma tendência de declínio nos coeficientes de morbimortalidade por febre tifóide; entretanto, estes dados devem ser vistos com cautela quanto à sua representativi- 
dade efidedignidade, pois 20\% do total deóbitos têm causa básica ignorada, existem dificuldades de diagnóstico laboratorial necessário para a identificação do agente etiológico e precariedades do sistema de informação. Esses indicadores apresentam importantes variações quando analisados por região, sendo as regiões N orte e N ordeste brasileiro onde se registram os números mais el evados, devido à precariedade das condições sanitárias, onde menos de $50 \%$ de sua população dispõem de algum tipo de abastecimento de água31.

Desde o final da década de 1970, surtos de enfermidades transmitidas por alimentos causados por Salmonella enteritidis passaram a ser relatados nos Estados Unidos e em vários países da Europa como o sorotipo mais predominante $^{47}$. No Brasil, a partir de 1993, este sorotipo passou a ser predominante, sendo os surtos re lacionados principalmente ao consumo de alimentos contendo ovos crus ou semicrus ${ }^{27,48}$.

Do ponto de vista epidemiológico, édegrande interesse a situação existente em São Paulo e provavelmenteem outras capitais brasileiras, em que a salmonelose infantil é uma doença nosocomial, na maioria das vezes, e o sorotipo dominante éSalmonella typhimurium que, aliás, é resistente à maioria dos antimicrobianos em uso terapêutico ${ }^{16}$. Em um estudo de prevalência da salmonelose, através de amostras fecais, em 56 pacientes de cinco hospitais e dois institutos de pesquisa no Vietnã, eque apresentavam quadros febris e diarréicos, constatou-se que do total de pacientes avaliados, 37,5\% apresentavam Salmonella typhimurium, ou seja, foi este o sorotipo mais freqüente dentre os casos avaliados nessa pesquisa, evidenciando que, independente da localização geográfica, pode-se encontrar sorotipos semelhantes ${ }^{40}$.

As alterações na legislação e na indústria avícola praticamente eliminaram as salmoneloses associadas com o consumo de ovos e derivados nas décadas de 1970 e 1980, nos Estados Unidos. Entre as medidas, estava a coleta várias vezes ao dia e o resfriamento imediato de ovos numatemperatura de $8^{\circ} \mathrm{C}$ e utilização de embalagem, permitindo espaçamento e boa ventilação para os ovos. A parentemente, essas medidas não têm surtido efeito no controle dos surtos por Salmonella enteritidis, que continua sendo uma das principais causas de toxinfecções al imentares em todo o mundo ${ }^{27}$.

A avicultura brasileira cresceu e sofreu inúmeras mudanças nas duas últimas décadas, devido ao desenvolvimento do mercado interno e aumento das exportações, aliado ao fato de ser a carne de frango um produto saudável e de preço acessível para a população. Entretanto, esta carne pode tornar-se veículo de transmissão de inúmeros microrganismos patogênicos; dentre eles, destaca-sea Salmonella spp., microrganismo este que aparece devido à operacionalização insatisfatória das diversas etapas do processamento das aves. De acordo com os autores, a elaboração e implantação deum plano de APPCC (Análise de Perigos e Pontos Críticos de Controle) na linha de produção de um abatedouro têm como objetivo obter uma descrição detal hada das características do produto e elaboração de fluxograma de processamento, analisando a partir desses dados o risco da ocorrência de perigos biológicos, químicos efísicos para a saúde do consumidor e adequação a legislação em vigor ${ }^{49}$.

No estudo analisando carcaças de frango adquiridas no comércio varejista de J oão Pessoa (PB), foram realizadas análises com sessenta cortes das carnes de frango, que estavam acondicionadas em embalagens à base de isopor e expostas à venda sob refrigeração. Quanto à análise microbiológica, teve como resultados para a Salmonella spp. (71,7\%), E. coli (95\%) e S. aureus $(43,35 \%)$ nas amostras analisadas, podendo assim demonstrar 0 alto índice de contaminação na amostragem analisada para esses três importantes patógenos ${ }^{38}$. Em outro estudo semelhante, analisando cem amostras de frango, os autores encontraram uma prevalência de 15\% para Salmonella spp. nas amostras avaliadas, ressaltando que esses resultados foram em decorrência da qualidade duvidosa do manejo posterior ao processamento, aumentando a probabilidade de ocorrência de salmoneloses ${ }^{37}$.

Pesquisando 68 carcaças de frango congeladas, provenientes de abatedouros do Estado de São Paulo, procedeu-se à pesquisa para Salmonella enteritidis, encontrando em treze $(19,1 \%)$ das amostras analisadas ${ }^{12}$, o que segundo a legislação vigente deveria estar ausente para este patógen $0^{50}$. Os autores concluíram que as doenças veiculadas por alimentos constituem atualmente um dos problemas de saúde mais disseminados e um importante fator de redução da produtividade econômica, reforçando a necessidade de controle sanitário que viseà redução dos índices de contaminação de carcaças de frango por S. enteritidis.

Analisando carnede sol comercializada em estabel ecimentos e feiras livres da cidade deCampina Grande (PB), foram analisadas vinte amostras, sendo dez à temperatura ambiente e as de- 
mais sob refrigeração, no período de julho a dezembro de 1995. As análises foram efetuadas para detectar a presença deSalmonella spp., constatando a presença desta bactéria em $40 \%$ (04) das amostras decarne de sol comercializadas à temperatura ambiente, e em $30 \%$ (03) das amostras sob refrigeração ${ }^{51}$. Os autores concluem que, por não haver diferença estatisticamente significativa entre a carnecomercializadaà temperatura ambienteesob refrigeração, há a necessidade de uma intervenção governamental urgente, uma vez que a produção é executada de forma primitiva e artesanal, não regulamentada; e a matéria-prima empregada é no geral de qualidade inferior, o que pode se tornar foco de transmissão de enteropatógenos.

Foram pesquisadas quinze amostras de carne bovina moída in natura, comercializadas em supermercados da região oeste de São Paulo (SP) e as análises efetuadas foram para a pesquisa de Staphylococcus aureus e Salmonella spp. Detectou-se a presença de Salmonella spp. em uma amostra e S. aureus em outra amostra. M esmo tendo sido encontrado patógenos em pequeno percentual na amostragem, os autores concluem que é preocupante o fato de que supermercados ondeforam col hidas as amostras sejam altamente conceituados e supostamente confiáveis, o que torna necessário um controle mais rigoroso por parte dos serviços de Vigilância Sanitári ${ }^{52}$.

Foi feito um estudo sobre a prevalência de Salmonella em 122 amostras de carne moída crua adquiridas em 33 açougues na cidade de Gaborone, em Botsuana, país localizado no sul da África, com coletas real izadas entreagosto de 2002 eabril de2003. Esseestudo foi promovido porquea Salmonella foi isolada da carne bovina e este resultado foi associado a casos de diarréias em crianças de Botsuana. Das amostras analisadas, 20\% (24/ 122), apresentaram positividade para Salmonella spp. Os autores descrevem vários fatores para justificar essa realidade, como manejo inadequado dos animais, principalmente durante o transporte em que os animais sofrem estresse e ocorre a contaminação cruzada entreos animais, aumento do consumo de carne bovina sem a infra-estrutura sanitária adequada nos matadouros e principalmente devido ao manuseio inadequado nos pontos de venda9. Os autores também enfatizam nesse estudo a necessidade da adoção do APPCC com o objetivo de reduzir ou eliminar a contaminação por patógenos naquele país.

A presença de Salmonella em suínos podere presentar um risco para a saúde pública, uma vez que tem se observado o aumento do número de surtos, devido ao consumo de produtos suínos contaminados presentes em diversos países. 0 autor escolheu para essa pesquisa uma granja de suínos, localizado na região do Vale do Taquari, no Rio Grande do Sul. Foram sorteados 105 animais clinicamente saudáveis e em fase de terminação ea amostragem foi material fecal individual dos suínos. Do total avaliado (105 animais) , 53 apresentaram Salmonella em seu conteúdo intestinal, classificadas em quinze sorotipos diferentes, demonstrando a alta prevalência da Salmonella e diversificação dos sorotipos. Os autores finalizam o estudo reforçando a importância da determinação da epidemiologia da infecção por Salmonella em rebanhos suínos, para traçar estratégias e programas de controle que diminuam o índice de suínos portadores de Salmonella spp. para o abate ${ }^{53}$. Os produtos de origem suína já são considerados importante fonte de infecção, sendo superados apenas por produtos de origem avícola ${ }^{54}$.

Em um estudo epidemiológico da prevalência de Salmonella não tifóide, em amostras fecais de 534 suínos saudáveis de treze províncias do sul do Vietnã, durante o ano de 2004, do total de animais analisados, $49,4 \%$ ou 264 suínos apresentavam no trato intestinal a Salmonella spp. Em decorrência desses achados, os autores fizeram um alerta, considerando que os suínos se mostraram um importante reservatório de Salmonella nas amostras analisadas, representando assim um fator de risco de toxinfecção alimentar para os consumidores no Vietnã ${ }^{40}$.

Existe um aumento do consumo mundial de peixes; entretanto, há evidências de que o consumo destes e outros frutos do mar possa estar associado aos surtos de origem alimentar no território iraniano. Para verificar a freqüência da contaminação por Salmonella, foram selecionados 39 peixes $\mathrm{H}$ ypophthalmichys molitrix, originários do $\mathrm{M}$ ar Cáspio, perto da costa iraniana. Os peixes foram eviscerados e depois submetidos ao processo de salga, na proporção de 30-35 $\mathrm{kg}$ de sal a cada $100 \mathrm{~kg}$ de peixe. Foi detectada a presença da Salmonella em uma amostra $(2,7 \%)$ do total ${ }^{36}$. Os autores justificam esse baixo nível de contaminação pelo fato que esse produto cárneo, apesar de ser susceptível à contaminação microbiológica, é comercializado em concentrações de $\mathrm{NaCl}$ superiores a $7 \%$. Foi mostrado que altas concentrações desse sal inibe o crescimento da Salmonella spp ${ }^{55}$. 


\section{Prevenção e controle}

Nos últimos dez anos, ocorreram importantes surtos de doenças emergentes transmitidas por alimentos no mundo, que alertaram as autoridades sanitárias dos países sobre a necessidade de tomar medidas para evitar o risco de transmissão, - que levou a FAO a criar a Organização Mundial do Comércio, quemotivou os países a revisar suas políticas, normas e estratégias de inocuidade para garantir que os alimentos consumidos pela população tenham as condições sanitárias apropriadas para facilitar o comércio internacional ${ }^{56}$.

A vacinação é um instrumento disponível para controle da febre tifóide, utilizada principalmente para profissionais de risco, como trabal hadores que entram em contato com esgotos; para pessoas que ingressam em áreas de alta endemicidade por ocasião de viagem ou quem habita regiões de incidência comprovadamente alta18, 31,45.

Recomenda-se ações de educação em saúde, destacando os hábitos de higi ene pessoal, principalmente a lavagem correta das mãos entre as pessoas que manipulam alimentos, observando cuidados na preparação, manipulação, armazenamento edistribuição de alimentos. As principais estratégias de prevenção devem ser: seleção da matéria-prima, utensílios e equi pamento cuidadosamentehigienizados; fornecimento deágua potável eadequado sistema detratamento delixo e esgoto; adoção de boas práticas de fabricação e implantação do sistema APPCC; afastamento dos portadores assintomáticos da área de produção e métodos de preservação e de transporte adequados. Todas essas ações estão em conformidade com as recomendações das autoridades de saúde pública em nível mundial2,31,37.

Para que os casos de salmonelose fiquem sobre controle, medidas devem ser adotadas, incluindo a vigilância freqüentee sistemática na linha de produção e distribuição de alimentos, porque um programa eficiente promove garan- tias na produção de alimentos seguros e redução nos custos. Os autores descrevem que após um ano da implantação de um programa de controle da Salmonella na Finlândia, a prevalência ficou abaixo de $1 \%$ no segmento da carne bovina, suína, aves e na produção de ovos, reduzindo conseqüentemente os surtos de salmoneloses ${ }^{8}$.

\section{Consideraçõesfinais}

A higiene dos alimentos consiste, portanto, na adoção de medidas preventivas e de controle, como a implantação do sistema APPCC, que se mostrou uma ferramenta eficiente para a remoção de agentes causadores de doenças, com o objetivo de conferir proteção específica contra as doenças transmitidas por alimentos, proporcionando redução nos custos egarantias no consumo de alimentos seguros do ponto de vista microbiológico.

A notificação e os registros epidemiológicos são uma importante fonte de informações para que os órgãos competentes de fiscalização e controle possam estimar quais os patógenos e grupos de alimentos possivelmente envolvidos em surtos de toxinfecção alimentar. Como exemplo, verifica-se a presença de vários sorotipos de Salmonella nos plantéis de suínos, dos quais a uns anos atrás não havia alta prevalência e que, na atualidade, representam, mundial mente, um grave problema de saúde pública.

Um outro fator é a importância econômica, pois ocorre um aumento da capacidade de produção da população economicamente ativa, em razão da segurança alimentar proporcionada por uma alimentação sem o risco de casos de salmoneloses.

0 mapeamento das doenças veiculadas por alimentos fornece subsídios para o desenvolvimento de medidas políticas, legislativas, priorização de áreas de pesquisa e avaliação de programas de controle de surtos epidêmicos. 


\section{Colaboradores}

NZS Shinohara, VB de Barros, SM C Jimenez, ECL Machado, RAF Dutra eJL de Lima Filho participaram igualmente de todas as fases de elaboração do artigo.

\section{Referências}

1. Santos LR, Nascimento VP, Flores M L. Salmonella enteritidis isoladas de amostras clínicas de humanos e de alimentos envolvidos em episódios de toxinfecções alimentares, ocorridas entre 1995 e 1996, no estado do Rio Grande do Sul. Higiene Alimentar 2002; 16(102/103): 93-99.

2. ICM SF. M icroorganismos de los alimentos. Acribia: Zaragoza; 2002.

3. Forsythe SJ. M icrobiologia da segurança alimentar. Porto Alegre: Artmed; 2002.

4. Germano PML. Prevenção e controle das toxinfecções de origem alimentar. Higiene Alimentar 1993; 7(27): 6-11.

5. Cardoso L, Araújo WM C. Parâmetros de qualidade em produtos prontos para consumo imediato e congelados artesanais comercializados no distrito Federal no período de 1997-2001. Higiene Alimen$\operatorname{tar} 2003 ;$ 17(109):40-44.

6. Silva CC, Rodrigues, M M, M artins BR. Toxinfecção alimentar por Salmonella em São Paulo/SP. Boletim Epidemiológico Paulista [periódico na Internet]. 2004 [acessado 2005 Abr 24]; 1(11). Disponível em: http://www.cve.saude.sp.gov.br/agencia/ bepal1 salmo.htm

7. Brasil. M inistério da Saúde. FUNASA. CENEPI. M ortalidade Brasil - 2004. Brasília: CENEPI/FU NASA; 2004.

8. Maijala R, Ranta J, Seuna E. The efficiency of the Finnish Salmonella Control Programme. Food Control 2005; 16(8):669-675.

9. M rema N, M puchane S, Gashe BA. Prevalence of Salmonella in raw minced meat, raw fresh sausages and raw burger patties from retail outlets in Gaborone, Botswana. Food Control 2006; 17(3):207-212.

10. Pena M EC, Iglessias ALH, Jimenez MAH. Brote por Salmonella enteritidis em trabajadores de um hospital. Salud Pública M éxico 2001; 43(3):211-216.

11. Suresh T, Hatha AAM, Screenivasa D. Prevalence and antimicrobial resistance of Salmonella enteritidis and other salmonellas in the eggs and eggstoring trays from retails markets of Coimbatore, south India. Food M icrobiology 2006; 23(3):294-299.

12. Tessari ENC, Cardoso ALSP, Castro AGM. Prevalência de Salmonella enteritidis em carcaças de frango industrialmente processadas. Higiene Alimentar 2003; 17(107):52-55.

13. Floweres FL. Salmonella. Food Technology 1988; 42(4):182-185.
14. Germano PML, Germano MIS. Higiene e vigilância sanitária de alimentos. São Paulo: Varela; 2003.

15. Pelczar JM, Chan ECS, Krieg NR. M icrobiologia, conceitos e aplicações: doenças transmitidas por água e alimentos. São Paulo: Makron Books; 1996.

16. Trabulsi LR, Alterthum LF. M icrobiologia. São PauIo: Atheneu; 2004.

17. Lourenço MCS, Reis EFM, Valls R. Salmonella enté rica subsp houtenae sorogrupo 0:16 em um paciente HIV positivo: relato de caso. Revista Instituto de M edicina Tropical de São Paulo 2004; 46(3):169-170.

18. Guerin PJ, Vold LAA, Viltsland P. Communicable disease control in a migrant seasonal workers population: a case sudy in Norway. Eurosurveillance 2005, 10(1-3):48-50.

19. Taitt CR, Shubin YS, Angel R. Detection of Salmonella enterica Serovar Typhimurium by using a Rapid, Array-Based Immunosensor. Applied and Environmental Microbiology 2004, 70(1):152-158.

20. Brasil. M inistério da Agricultura, Pecuária e Abastecimento. Projeções do Agronegócio. M undial e Brasil. Brasília: M inistério da Agricultura, Pecuária e A bastecimento; 2005.

21. Connor BA, Schwartz E. Typhoid and paratyphoid fever in travellers. The Lancet Infectious Diseases 2005; 5(10):623-628.

22. Franco BDGM, Landgraf M. M icrobiologia dos alimentos. São Paulo: Atheneu; 2004.

23. Jawetz M, Adelberg E. M icrobiologia médica. Rio de Janeiro: Guanabara Koogan; 2006.

24. Mims C, Playfair J, Roitt I. M icrobiologia médica. Rio de Janeiro: Elsevier; 2005.

25. Tortora GJ, Funke BR, Case CL. M icrobiologia. Porto Alegre: Artmed; 2005.

26. Haimovich B, Venkatesa M M. Shiguella e Salmonella: death as a means of survival. M icrobes and Infection 2006; 8(2):568-577.

27. Silva EM, Duarte A. Salmonella Enteritidis em aves: retrospectiva no Brasil. Revista Brasileira de Ciência Avícola 2002; 4(2):85-100.

28. D'aoust JY. Salmonella and international trade. International Journal of Food Microbiology 1994; 24(4):11-31.

29. Huang $\mathrm{H}$. Evaluation of culture enrichment for use with Salmonella detection in Immunoassay. International Journal of Food M icrobiology 1999; 51(23) :85-94. 
30. Pinto UM, Cardoso RR, Vanetti MCD. Detecção de Listeria, Salmonella e Klebsiella em serviço de alimentação hospitalar. Revista de Nutrição 2004; 17(3):319-326.

31. Brasil. M inistério da Saúde. Fundação Nacional da Saúde (FUNASA). Guia de Vigilância Epidemiológica. Brasília: Ministério da Saúde; 2002.

32. Ukuku DO. Effect of sanitizing treatments on removal of bacteria from cantaloupe surface, and recontamination with Salmonella. Food M icrobiology 2006; 23(3):289-293.

33. Silva Jr EA. M anual de controle higiênico-sanitário em serviços de alimentação. São Paulo: Varela; 2005.

34. M itakakis T, Sinclair M, Fairley C, Lightbodyl P, Leder K, Hellard M. Food safety in family homes in Melbourne, Australia. Journal of Food Protection 2004; 64(4):818-822.

35. Evangelista J. Tecnologia de alimentos. São Paulo: Atheneu; 2002.

36. Basti AA. Bacterial pathogens in fresh, smoked and salted Iranian fish. Food Control 2006; 17(3):183-188.

37. Reuben A, Treminio H, Arias M. Presencia de Escherichia coli 0157:H 7, Listeria monocytogenes y Salmonella spp. en alimentos de origen animal en Costa Rica. Archivos Latinoamericanos de Nutrición 2003; 53(4):389-392.

38. Silva JA, Azevedo GA, Barros CMR. Incidência de bactérias patogênicas em carne de frango refrigerada. Higiene Alimentar 2002; 16(100):97-101.

39. Schneitz C. Competitive exclusion in poultry - 30 years of research. Food Control 2005; 16(8):657-667.

40. Vo ATT, Duijikeren EV, Fluit AC. Distribuition of Salmonella enterica Serovar from humans, livestock and meat in Vietnam and dominance of Salmonella Typhimurium Phage Type 90. Veterinary M icrobiology 2006; 113(1-2):153-158.

41. Allende A, M CEvoy JL, Luo Y, Artes F, Wang CY. Effectiveness of two-sided UV-C treatments in inhibiting natural microflora and extending the shelflife of minimally processed "Red Oak Leaf" lettuce. Food M icrobiology 2006; 23(3):241-249.

42. Jay JM. Microbiologia de alimentos. Porto Alegre: Artmed; 2005.

43. Wells SJ, Fedorka-Cray PJ, Dargartz DA. Faecal shedding of Salmonella spp. By dairy cows on farm and at cull cow markets. Journal of Food Protection 2001; 64(1):3-11.

44. Paiva PC, Borges RG, Panetta JC. Freqüência de quadros gastroentéricos em aeronautas: Pressupostas ligação com toxinfecções alimentares. Higiene Alimentar 2000; 14(75):13-23.
45. Crump JA, Luby SP, Mintz ED. The global burden of typhoid fever. Bulletin of the Word Health Organization 2004; 82(5):346-353.

46. Riedel G. Controle sanitário dos alimentos. São PauIo: Atheneu; 2005.

47. Duijkeren V, Wannet E, Houwers WJ, Van PN. Serotype and phage type distribution of Salmonella strains isolated from humans, cattle, pigs, and chickens in the Netherlands from 1984 to 2001. Journal Clinical Microbiology 2002; 40(11):3980-3985.

48. Peresi JTM, Almeida IAZC, Lima SI. Surtos de enfermidades transmitidas por alimentos causados por Salmonella Enteritidis. Rev. Saúde Pública 1998; 32(5):477-483.

49. Carvalho LT, Costa PS, Carvalho, ALT. Análise de Perigos e Pontos Críticos de Controle na linha de produção de frango inteiro congelado. Higiene Alimentar 2002; 16(95):34-41.

50. Brasil. M inistério da Saúde. Secretaria de Vigilância Sanitária. Resolução nº 12 de 2 de janeiro de 2001. Dispõe sobre Regulamento Técnico sobre Padrões M icrobiológicos para Alimentos. Diário Oficial da União 2001; 10 jan.

51. Leite Jr AFS. Avaliação da qualidade microbiológica da carne de sol, comercializada à temperatura ambiente ou sob refrigeração, em Campina Grande, PB. Higiene Alimentar 2000 14(68/69):87-92.

52. M otta M RA, Belmonte M A, Panetta JC. Avaliação microbiológica de amostras de carne moída comercializada em supermercados da Região Oeste de são Paulo. Higiene Alimentar 2000; 14(78/79):59-62.

53. Michael GB, Simoneti R, Cardoso MRI. Sorotipos de Salmonella isolados em uma propriedade de suínos de terminação no sul do Brasil. Ciência Rural 2002; 32(3):525-527.

54. Baum D. Risk factors associated with increased seroprevalence of Salmonella in finishing swine. In: Proceedings of the 15th IPVS Congress; 5-9 July 1998; Birmingham, England.

55. Koneman EW, Allen SD, Janda M W. Diagnóstico microbiológico: texto e atlas. Rio de Janeiro: MEDSI; 2001.

56. Organização Pan-Americana da Saúde. HACCP: instrumento essencial para a inocuidade de alimentos. Buenos Aires: OPAS/IN PPAZ; 2001.

Artigo apresentado em 03/05/2006

Aprovado em 05/09/2006

Versão final apresentada em 10/08/2007 